\title{
Advances in Radiotherapy in Operable Rectal Cancer
}

\author{
Aravind Suppiah $^{\text {a }}$ John E. Hartley ${ }^{a} \quad$ John R.T. Monson ${ }^{b}$ \\ ${ }^{a}$ Academic Surgical Unit, University of Hull and Castle Hill Hospital, Cottingham, UK; \\ bUniversity of Rochester Medical Centre, Rochester, N.Y., USA
}

\section{Key Words}

Rectal cancer $\cdot$ Radiotherapy $\cdot$ Chemotherapy $\cdot$ Adjuvant treatment

\begin{abstract}
Aims: Radiotherapy (RT) reduces local recurrence in rectal cancer but the optimal treatment schedule is unknown. Relevant questions in designing optimal therapy are set out. This review identifies evidence that influences current practice and shapes future trials in treatment of operable rectal cancer. Methods: PubMed and MEDLINE search. Results: RT reduces local recurrence and pre-operative treatment is superior to post-operative treatment. Longer interval to surgery and concurrent chemotherapy are associated with greater downstaging, although influence on sphincter preservation and survival is minimal. Short-course RT (SCRT) demonstrates lower recurrence, but with long-term dysfunction and minimal survival benefit. The role of SCRT should be re-evaluated to encompass new criteria/areas. Conclusion: SCRT should be used selectively rather than as a blanket treatment policy. SCRT compounds functional morbidity caused by mesorectal excision which may be excessive in some patient groups, especially early-stage rectal cancer or frail elderly patients. RT and local excision may be a feasible surgical alternative in these groups. Alternatively, SCRT and delayed surgery may be a future alternative to cur-
\end{abstract}

rent long-course chemoradiotherapy. As survival is only marginally affected despite low local recurrence, future trials should aim to address metastatic disease. End points which incorporate function and quality of life must be used.

Copyright $\odot 2009$ S. Karger AG, Basel

\section{Introduction}

Local recurrence is a devastating event following curative treatment for operable rectal cancer. Total mesorectal excision (TME) has led to significant reduction in local recurrences from $40 \% 20$ years ago to less than 15\% $[1,2]$. Neo-adjuvant and adjuvant therapies are used to further reduce local recurrence. Trials on both sides of the Atlantic have demonstrated clear benefit of these treatments but at the expense of increased morbidity and toxicity. Hence, optimal regimes are yet to be determined as contentious issues need to be addressed when designing best treatment. Several trials attempt to answer the more relevant questions listed below. Although the eventual aim of this review is to discuss radiotherapy (RT) in early operable tumours, most of the evidence leading up to current practice is from trials of (chemo)radiotherapy performed in locally advanced tumours and thus deserve inclusion.

\section{KARGER}

Fax +4161306 1234 E-Mail karger@karger.ch www.karger.com
(C) 2009 S. Karger AG, Basel

0253-4886/09/0263-0187\$26.00/0

Accessible online at:

www.karger.com/dsu
Aravind Suppiah

Academic Surgical Unit, Castle Hill Hospital

Castle Road

Cottingham HU16 5JQ (UK)

Tel. +44 1482623 225, Fax +44 1482623 274, E-Mail aravindsuppiah@hotmail.com 
Table 1. Results of the Colorectal Cancer Collaborative Group meta-analysis [3]

\begin{tabular}{cllc}
\hline Overall survival & Radiotherapy & No radiotherapy & \\
5 years & 45.0 & 42.1 & NS \\
10 years & 26.9 & 25.3 & NS \\
\hline Local recurrence & Pre-operative RT & No pre-operative RT & \\
5 years & 12.5 & 22.2 & $<0.00001$ \\
10 years & 16.7 & 25.8 & $<0.00001$ \\
Any recurrence & & & \\
5 years & 45.9 & 52.9 & $<0.00001$ \\
10 years & 55.1 & 60.8 & $<0.00001$ \\
\hline Any recurrence & Post-operative RT & No post-operative RT & \\
5 years & 15.3 & 22.9 & $<0.0002$ \\
10 years & 50.3 & 53.8 & NS \\
\hline
\end{tabular}

Figures indicate percentages. NS = Not significant. only

Pre- or post-operative surgery + surgery versus surgery

- Colorectal Cancer Collaborative Group meta-analysis

Long-course (chemo)radiotherapy

- Pre-operative chemoradiotherapy (CRT) versus post-operative CRT (German Rectal Cancer Trial)

- Pre-operative CRT versus pre-operative RT (EORTC 22921, FFCD 9203)

Short-course RT (SCRT) + surgery versus surgery only

- Stockholm I and II, Swedish Rectal Cancer Trial, Dutch TME

- SCRT or post-operative selective long-course CRT (LCCRT) - MRC-CR07

What is the optimal interval between SCRT and surgery?

- Lyon 90-01, Stockholm III (in progress)

Pre-operative SCRT versus pre-operative LCCRT

- Polish Trial, TROG 44 (in progress)

Morbidity and toxicity of $R T$

- RT or CRT: Cochrane Database Review

- SCRT: Stockholm I and II, Swedish Rectal Cancer Trial, Dutch TME, MRC-CR07

\section{Materials and Methods}

A PubMed and MEDLINE literature search was performed. Exploded search terms used were 'rectal cancer', 'radiotherapy', 'chemotherapy', 'neoadjuvant' and 'adjuvant'. Relevant trials and associated publications were selected for discussion.

\section{Pre-/Post-Operative RT and Surgery versus Surgery Only}

\section{Colorectal Cancer Collaborative Group}

A meta-analysis of 22 trials prior to 1987 comparing pre-operative RT (6,350 patients, 14 trials) or post-operative RT (2,157 patients, 8 trials) with surgery alone demonstrated that pre-operative RT led to decreased 5and 10-year local recurrence but no difference in overall survival (table 1) [3]. Analysis of biologically effective radiological doses was performed by stratification into $<20,20-29$ and $>29$ Gy. Individual trial doses varied between 7.5-37.5 Gy for pre-operative RT and 35.4-43.8 Gy for post-operative RT. Patients treated with biologically higher doses ( $>29$ Gy) had lower recurrence rates (57 vs. $37 \%$ ). In summary, the control group had high cancer-specific mortality compared with the irradiated group. Survival benefit was greatest in patients receiving high-dose pre-operative RT $>30$ Gy leading to overall reduction in death of $22 \%$ compared with controls. These results suggest that RT, whether pre- or post-operative, confers benefit beyond that of surgery alone. Once this was established, the question was whether RT should be administered pre- or post-operatively. Comparisons of trials were biased as individual trials of preoperative RT (Stockholm I and II, Swedish Rectal Cancer Trial) used higher radiological doses than those of post-operative RT, and the importance of achieving high biological dose had been demonstrated. The pivotal trial in establishing pre-operative RT was the German Rectal Cancer Trial. 


\section{Long-Course Chemoradiation}

Pre-operative treatment is theoretically superior to post-operative treatment due to well-oxygenated pre-operative tissue, tumour downstaging and better treatment compliance $[4,5]$. The low RT dose fraction (as opposed to SCRT) also permitted concomitant chemotherapy (CT) which increases downstaging, theoretically increasing circumferential resection margin (CRM) clearance rates and sphincter preservation, and possibly even eliminating microscopic metastatic disease but at the expense of increased toxicity, especially in radiologically overstaged patients [6]. Two further European trials (EORTC 22921, FFCD 9203) around the same time compared preoperative RT with pre-operative chemoradiotherapy. The combination of these studies established pre-operative LCCRT as the optimal form of irradiation in locally advanced $\mathrm{T} 3 / \mathrm{T} 4$ cancers.

\section{German Rectal Cancer Trial}

The German Rectal Cancer Trial [7] randomised 823 with endorectal ultrasound (ERUS)/computed tomography-staged T3/4 M0 rectal cancer patients to pre-operative LCCRT or post-operative LCCRT. Pre-operative LCCRT led to superior local control but no difference in distant metastases, disease-free survival or overall survival. The concept of RT modulating tumour behaviour but not altering disease-free survival is discussed later ('Swedish, Dutch TME Trial'). The important result was that pre-operative LCCRT had significantly better compliance and downstaging than post-operative LCCRT, whereas post-operative LCCRT was poorly tolerated and had higher ( 40 vs. $26 \%$ ) grade $3 / 4$ toxicity. Furthermore, the concerns that pre-operative LCCRT delayed surgery leading to disease progression or increased surgical morbidity was disproven. Hence, pre-operative LCCRT was recommended as standard of care, providing better local control (but not survival) with superior compliance and safety.

\section{Pre-Operative RT or Pre-Operative CRT}

\section{European Organisation for Research and Treatment of} Cancer Radiotherapy Group Trial 22921

This trial [8] randomised 1,011 patients with resectable T3/4 rectal cancer staged by computed tomography and/or ERUS to four intervention arms: pre-operative RT only, pre-operative RT + post-operative CT, pre-operative LCCRT only and pre-operative LCCRT + post-op- erative CT [8]. The trial was powered to detect $10 \%$ difference in overall survival between the two pre-operative treatment groups and the two post-operative treatment groups with analysis at a median follow-up of 5.4 years (table 2). Post-operative treatment was again associated with poor compliance and greater toxicity as $27 \%$ (136/506) of patients did not receive allocated post-operative treatment due to post-operative complications (33), disease progression (25), no surgery (22) and patient refusal (25). Furthermore, only 43\% (207/506) received $95-105 \%$ of the target dose. Acute toxicity was seen in more than half $(58 \%, 214 / 506)$ of those receiving post-operative CT. The intervention arms differed from the German Rectal Cancer Trial but the emerging theme was that post-operative treatment is associated with poor compliance, higher toxicity and decreased disease control.

The second crux of this trial was the comparison of pre-operative RT without CT with pre-operative LCCRT. Pre-operative LCCRT led to greater downstaging, smaller tumours, less advanced nodal status and less frequent perineural, lymphatic and venous invasion. The 5-year local recurrence rates are shown in table 2. Overall, high recurrence is attributed to non-TME surgery. Patients receiving pre-operative RT without post-operative treatment had the highest local recurrence. There was no difference in 5-year overall or disease-free survival between pre-operative RT and pre-operative LCCRT. It is possible that this was due to more patients receiving post-operative CT in the pre-operative RT group due to lesser downstaging compared with pre-operative LCCRT. However, subgroup analysis of patients with and without adjuvant CT demonstrated no survival difference. Hence, pre-operative LCCRT leads to superior downstaging and local control, which was confirmed in a recent meta-analysis [6] (table 3).

Interestingly, there was a non-significant increase in 2-year disease-free survival and 4-year overall survival in patients receiving post-operative CT. The recently published long-term results report that this survival benefit with post-operative CT was only in ypT0-2 (initially staged T3/4) [9]. This suggests that the downstaging response is an indicator of chemo-/radio-sensitive tumours, which may be used as future selection criteria for patients who benefit most from CT. However, it is important to balance the toxicity of post-operative CT against the modest potential survival benefit, in a highly select group of patients with favourable tumours.

The FFCD 9203 randomised 762 patients with ERUS/ computed tomography-staged digitally accessible T3/4 rectal cancer to pre-operative RT ( $45 \mathrm{~Gy}, 25 \times 1.8 \mathrm{~Gy}$ ) or 
Table 2. Major trials on pre-operative radiotherapy versus pre-operative chemoradiotherapy

\begin{tabular}{|c|c|c|c|c|c|c|c|}
\hline Trial & Arms & FU & Overall survival & Disease-free survival & LR & Path. resp. & SP \\
\hline $\begin{array}{l}\text { EORTC } \\
22921\end{array}$ & $\begin{array}{l}\text { Pre-op RT } \\
\text { Pre-op RT + } \\
\text { post op CT } \\
\text { Pre-op CRT } \\
\text { Pre-op CRT + } \\
\text { post-op CT }\end{array}$ & 5.4 years & $\begin{array}{l}65.8 \% \\
p=0.84 \\
\text { Post-op CT: } 67.2 \% \\
\text { No post-op CT: } 63.2 \% \\
p=0.12\end{array}$ & $\begin{array}{l}5 \text { years } \\
\text { Post-op CT: } 58.2 \% \\
\text { No post-op CT: } 52.2 \% \\
\mathrm{p}=0.13\end{array}$ & $\begin{array}{l}5 \text { years } \\
17.1 \% \\
9.6 \%\end{array}$ & $\begin{array}{l}5.3 \% \\
p=0.0001\end{array}$ & $\begin{array}{l}55.6 \% \\
p=0.05\end{array}$ \\
\hline $\begin{array}{l}\text { FFCD } \\
9203\end{array}$ & $\begin{array}{l}\text { T3/4 Nx M0 } \\
\text { Pre-op RT } \\
\text { Pre-op CRT }\end{array}$ & $\begin{array}{l}81 \text { months } \\
(17-145)\end{array}$ & $\begin{array}{l}5 \text { years } \\
67.9 \% \\
67.4 \% \\
p=0.684\end{array}$ & $\begin{array}{l}5 \text { years } \\
55.5 \% \\
59.4 \%\end{array}$ & $\begin{array}{l}5 \text { years } \\
16.5 \% \\
8.1 \% \\
p=0.004\end{array}$ & $\begin{array}{l}3.6 \% \\
11.4 \% \\
\mathrm{p}<0.05\end{array}$ & $\begin{array}{l}41.7 \% \\
42.3 \%\end{array}$ \\
\hline $\begin{array}{l}\text { Polish } \\
\text { Trial }\end{array}$ & $\begin{array}{l}155 \text { SCRT + } \\
\text { TME in } 7 \text { days } \\
157 \text { CRT }(28 \times \\
1.8 \text { Gy }+5 \text { FU/LV }) \\
+ \text { TME } 6-8 \text { weeks }\end{array}$ & $\begin{array}{l}48 \text { months } \\
(31-69)\end{array}$ & $\begin{array}{l}4 \text { years } \\
67.2 \% \\
66.2 \% \\
p=0.960\end{array}$ & $\begin{array}{l}4 \text { years } \\
58.4 \% \\
55.6 \% \\
p=0.820\end{array}$ & $\begin{array}{l}4 \text { years } \\
10.6 \% \\
15.6 \% \\
p=0.21\end{array}$ & $\begin{array}{l}0.7 \% \\
16.1 \% \\
\text { significant }\end{array}$ & $\begin{array}{l}61.2 \% \\
58 \% \\
p=0.57\end{array}$ \\
\hline
\end{tabular}

$\mathrm{FU}=$ Follow-up; $\mathrm{LR}=$ local recurrence; Path. resp. $=$ pathological response $\mathrm{SP}=$ sphincter preservation.

Table 3. Cochrane systematic review of pre-operative RT versus pre-operative CRT [6]

\begin{tabular}{lcc}
\hline & CRT & RT \\
\hline Five-year local recurrence $^{1}$ & $9.4 \%$ & $16.5 \%$ \\
& $71 / 754$ & $122 / 740$ \\
Five-year disease-free survival & $57.5 \%$ & $54.9 \%$ \\
& $507 / 881$ & $479 / 872$ \\
Five-year overall survival & $63.9 \%$ & $65.2 \%$ \\
& $644 / 1,007$ & $647 / 993$ \\
Grade 3/4 toxicity ${ }^{1,2}$ & $14.9 \%$ & $5.1 \%$ \\
& $151 / 1,015$ & $52 / 1,017$ \\
Complete pathological response ${ }^{1}$ & $11.8 \%$ & $3.5 \%$ \\
& $129 / 1,096$ & $39 / 1,105$ \\
Sphincter preservation & $49.6 \%$ & $47.6 \%$ \\
& $551 / 1,111$ & $527 / 1,108$ \\
Thirty-day mortality & $2.8 \%$ & $1.9 \%$ \\
& $31 / 1,122$ & $21 / 1,117$ \\
Morbidity & $21.7 \%$ & $24.9 \%$ \\
& $217 / 998$ & $248 / 996$
\end{tabular}

${ }^{1}$ Statistical significance.

${ }^{2}$ Significant sample heterogeneity. pre-operative LCCRT [10] (table 2). This study was powered to detect $10 \%$ difference in overall survival. LCCRT led to better pathological response (11.4 vs. 3.6\%) and lower local recurrence at 5 years (8.1 vs. $16.5 \%)$ but with higher grade $3 / 4$ toxicity (14.6 vs. $2.7 \%$ ), which was considered acceptable in exchange superior local control. The results of the German, EORTC and FFCD trials confirmed pre-operative LCCRT to be treatment of choice in locally advanced T3/4 rectal cancer. At around the same time, results from large trials on an alternative form of pre-operative RT, SCRT, were emerging.

\section{Pre-Operative SCRT ( 5 × Gy) and Surgery versus Surgery Only}

SCRT was designed to deliver a minimum biological dose within a short period. Theoretically, LCCRT, which uses small doses with multiple fractions over a prolonged period of time (46 Gy, 25 fractions of 1.8-2 Gy over 6 weeks), and the subsequent interval to surgery could lead to disease progression and unresectability [11]. Shorter 
courses of RT could decrease the duration to surgery but would require higher dose fractions to achieve the total biological dose. The importance of achieving high total biological dose for superior disease control was already demonstrated in the meta-analysis by Gray et al. [3] and the German trial [12]. Using calculations for cumulative radiation effect and correcting for late adverse effects due to higher fractions over shorter duration, $5 \times 5.1 \mathrm{~Gy}$ was considered the optimal compromise [11]. The major trials of pre-operative SCRT versus surgery alone are the Stockholm I and II, Swedish Rectal Cancer Trial and Dutch TME Trial, and MRC-CR07, which is soon to be published [pers. commun.]. The result of these trials and the long-term follow-up represent one of the most conclusive evidence-based data for any adjuvant treatment (table 4).

\section{Swedish Rectal Cancer Trial}

The Swedish Rectal Cancer Trial [13] randomised 1,168 patients to pre-operative SCRT and surgery or surgery only. The median 13-year follow-up represents the longest follow-up of any adjuvant therapy. Pre-operative SCRT led to decreased local recurrence with increased disease-free and overall survival when all stages were included [13] (table 4). Local recurrence was similarly reduced when individual stages were analysed but overall and disease-free survival was unchanged (except stage 1 disease-free survival). This could be due to the small sample sizes in individual stages and the long follow-up. This would lead to a trend towards better (but not necessarily significant) survival with SCRT as seen in this study. Alternatively, SCRT may only be modulating local recurrence rates without affecting survival.

This hypothesis, when combined with observations that SCRT was associated with delayed recurrences after initial surgery (12 years), shorter time to death from recurrence, and no difference in survival or metastases (34\% in each group), suggests that SCRT may be modulating the local behaviour of tumours by reducing the shortterm local recurrence rates. It has less marked effect on the overall number of recurrences in the long-term, and simply 'smooths out' the recurrence curve over several years, as opposed to the non-irradiated group where most recurrences occur within the first 24-36 months. Also, SCRT does not affect long-term systemic disease. Given sufficient follow-up, both groups' disease-specific curves could be expected to converge.

This effect should be taken into account when selecting patients for SCRT. Frail patients with stage II cancer and limited survival (e.g. $<5$ years) due to medical mor- bidity may benefit from reduction in early recurrence. Similarly, frail patients with stage III cancers, traditionally offered pre-operative LCCRT, may also benefit from SCRT due to (a) the reduction in early recurrence, (b) SCRT logistics (e.g. less hospital visits, shorter treatment duration and interval to surgery), (c) less toxicity. In these patients, SCRT would be a feasible alternative as longterm disease control is not as important. Alternatively, young patients with early (stage I/II) tumours may instead benefit from adjuvant CT to reduce systemic metastases, which is the main factor affecting disease-free survival, rather than experience significant SCRT-related functional morbidity with minimal or no benefit in longterm local or systemic recurrence. These are important considerations in selecting patients for pre-operative SCRT, rather than a 'blanket' treatment of all stage I/II tumours.

The survival benefit of the irradiated group (all stages included) cannot entirely be attributed to the provision of SCRT only. TME was not routine practice and this is reflected in the high recurrence rate (26\%) in the surgery alone group. Other known prognostic indicators such as CRM were also not reported $[14,15]$. This leads to an exaggerated survival benefit attributed to SCRT. Even so, the trial proposed beneficial effects of SCRT even with standardised TME. This was investigated in the Dutch TME Trial.

\section{Dutch TME Trial}

This trial [16] established the benefit of pre-operative SCRT above that obtainable by TME surgery. This trial randomised 1,861 patients to receive SCRT or no SCRT prior to standardised TME surgery. The 5-year local recurrence rates were significantly lower in the SCRT group but without differences in overall survival (table 4). This trial addressed several contentious issues within the Swedish Trial. Firstly, TME was standardised resulting in local recurrence of $5.3 \%$ at 2 years, which is lower than in the Swedish Trial (26\%), and more consistent with modern TME practice $[13,16]$. Secondly, SCRT reduced local recurrence at 2 and 5 years despite TME surgery, suggesting a benefit above that obtainable by TME. Thirdly, SCRT demonstrated no reduction in local recurrence in stage I cancers. This conflicts with the postulation in the Swedish trial that SCRT remains beneficial in stage 1 cancer, even with TME [13]. The Dutch trial demonstrates TME alone can lead to $0.7 \%$ recurrence in stage I cancer. The risk:benefit of SCRT is thus unlikely to be of use. The modest $0.2 \%$ improvement in local control could be extrapolated to suggest 500 patients would be irradiated un- 
necessarily to reduce one recurrence. Finally, lower recurrence was seen in stage II and III cancer, confirming that the beneficial effects of SCRT are above those obtainable by TME. However, this benefit was restricted to those patients with 'good' TME surgery. Later analysis reported that SCRT reduced local recurrence only if patients had adequate CRM resections, i.e. SCRT does not compensate for 'bad' surgery [17].

The long-term results show a less beneficial reduction in recurrence at median 6.1 years (5.6 vs. $10.9 \%$ ). This supports the earlier postulation that SCRT may not cure local recurrence, but alters biological behaviour, thus reducing recurrence rate in the early post-operative period but not the long-term probability of recurrence, i.e. SCRT postpones recurrence. In addition, the lower local recurrence did not translate to survival benefit (64 vs. $63 \%$ ) probably due to systemic metastases. Observations from these 2 trials suggest that SCRT can reduce the yearly risk of local recurrence, but with minimal reduction in the total number of recurrences in the long-term, no effect on systemic recurrence and does not translate to significant difference in survival. This would suggest that SCRT should only be used selectively in stage I/II cancers, rather than as a blanket approach as discussed earlier ('Swedish Rectal Cancer Trial').

SCRT reduced recurrence in patients with TNM stage III disease, positive CRM involvement, and lesions between $5-10 \mathrm{~cm}$ at a median follow-up of 6 years [18]. The first observation supports previous conclusions - SCRT does not feasibly improve recurrence rates in stage I/II cancer beyond those obtainable by TME. Hence, unnecessarily large numbers of patients are irradiated, with resulting long-term toxicity, in return for negligible or no benefit. The second subgroup analysis confirms that SCRT does not compensate for 'inadequate' TME surgery with CRM margin involvement [17-19]. The third observation that lesions between $5-10 \mathrm{~cm}$ from the anal verge benefit from SCRT but not those more proximal /distal lesions is probably attributable to difficult dissection of tumours $<5 \mathrm{~cm}$ from the anal verge, leading to involved CRM or inadequate TME clearance. The combination of the Swedish and the more contemporary Dutch TME Trial is pivotal in starting routine SCRT for early rectal cancers in several European countries. However, SCRT is once again under scrutiny as emerging evidence from longer-term follow-up suggests significant anorectal dysfunction, which is discussed later.

The most recent trial in the UK, MRC-CR07, randomised 1,350 operable rectal cancer patients to pre-operative SCRT or selective post-operative LCCRT if resec- tion margins were involved [20]. SCRT demonstrated decreased local recurrence but no difference in overall survival, which is similar to the early results of the Dutch trial (table 4). Longer follow-up and stage-specific analysis will be valuable in assessing whether SCRT is beneficial, especially in early stage (T1/2) cancer. The full results of the trial are due to be published soon [pers. commun.]. Another strength of this trial is that it is among the few which incorporated objective gastrointestinal/ sexual function and quality of life assessment. The results are discussed later. Surprisingly, very few trials compare pre-operative SCRT with pre-operative LCCRT.

\section{Pre-Operative SCRT versus Pre-Operative LCCRT}

\section{Polish Trial}

The Polish trial [21] compared pre-operative SCRT + TME within 7 days with pre-operative LCCRT + TME at 4-6 weeks. 316 (T3/4) patients were randomised to detect a $15 \%$ difference in sphincter preservation. Pre-operative SCRT had less grade $3 / 4$ toxicity (3 vs. $18 \%$ ), better compliance ( 97.9 vs. $69.2 \%$ ) and similar post-operative toxicity (28.3 vs. $27 \%$ ). However, pre-operative LCCRT had higher complete pathological response rate (16.1 vs. $0.7 \%$ ) and lower circumferential margin involvement (4.4 vs. $12.9 \%$ ), which did not translate into improved survival or recurrence at a median follow-up of 48 months (tables 2 , 4). This could be attributed to the lower compliance (69\%) with LCCRT, thus reducing the survival benefit, and the small sample size designed to detect a large difference in sphincter preservation, which does not correspond to pre-operative downstaging or survival $[10,22]$. Radiological modalities are unable to accurately predict pathological response. Even if methods could accurately predict complete response (T0), there is scepticism about the long-term behaviour of 'sterilised tumour' left in situ. Habr-Gama [23] demonstrated similar recurrence rates between patients treated non-surgically following CRT and those with surgery after CRT. However, these results have not been reproduced elsewhere. Hence, surgeons are unlikely to change surgical plan and hence alter sphincter preservation rates, even if complete pathological response could be obtained or accurately predicted radiologically.

A consistent problem with investigating survival of pre-operative treatments in trials using selective adjuvant CT (this trial and EORTC 22921) is that the survival analysis is biased by the higher provision of adjuvant CT in the group displaying lesser downstaging. The lower downstaging effect seen after SCRT would mean more 
Table 4. Results of SCRT trials

\begin{tabular}{|c|c|c|c|c|}
\hline Study & Design & Follow-up & Results & Conclusion/remarks \\
\hline $\begin{array}{l}\text { MRC-CR07 } \\
{[20]}\end{array}$ & $\begin{array}{l}674 \text { SCRT + TME } \\
676 \text { TME + selective } \\
\text { post-op CRT }(25 \times 5 \\
\text { Gy }+5 \text { FU/LV })\end{array}$ & $\begin{array}{l}\text { median } \\
3 \text { years }\end{array}$ & $\begin{array}{l}\text { 3-year local recurrence } \\
\text { SCRT: } 4.7 \text { vs. } 11.1 \% \text { CRT ( } \mathrm{p}=0.000004 \text { ) } \\
\text { (no difference in stage I cancer) } \\
\text { 3-year disease-free survival } \\
\text { SCRT: } 79.5 \text { vs. } 74.9 \% \text { CRT } \\
\text { 3-year overall survival } \\
\text { SCRT: } 80.8 \text { vs. } 78.7 \% \text { CRT }\end{array}$ & $\begin{array}{l}\text { SCRT superior to selective post- } \\
\text { operative CRT (positive margins) } \\
\text { for local recurrence and disease-free } \\
\text { survival, but not overall survival. } \\
\text { SCRT local recurrence benefit } \\
\text { maintained in subset analysis of } \\
0-5,5-10 \text { and }>10 \mathrm{~cm} \text { from anal } \\
\text { verge but not stage I cancer. } \\
\text { Morbidity data in table } 5 \text {. }\end{array}$ \\
\hline $\begin{array}{l}\text { Polish Trial } \\
{[21]}\end{array}$ & $\begin{array}{l}155 \text { SCRT }+ \\
\text { TME in } 7 \text { days } \\
157 \text { CRT }(28 \times \\
1.8 \text { Gy }+5 \text { FU/LV }) \\
+ \text { TME } 6-8 \text { weeks }\end{array}$ & $\begin{array}{l}\text { median } \\
48 \text { months } \\
(31-69)\end{array}$ & $\begin{array}{l}\text { 4-year overall survival } \\
\text { SCRT: } 67.2 \text { vs. } 66.2 \% \text { CRT }(\mathrm{p}=0.960) \\
\text { 4-year disease-free survival } \\
\text { SCRT: } 58.4 \text { vs. } 55.6 \% \text { CRT }(\mathrm{p}=0.820) \\
\text { 4-year local recurrence } \\
\text { SCRT: } 10.6 \text { vs. } 15.6 \% \text { CRT }(\mathrm{p}=0.210) \\
\text { sphincter preservation } \\
\text { SCRT: } 61.2 \text { vs. } 58 \% \text { CRT }(\mathrm{p}=0.57)\end{array}$ & $\begin{array}{l}\text { CRT leads to increased downstaging } \\
\text { and tumour response but higher } \\
\text { pre-operative toxicity and low } \\
\text { compliance. Sphincter preservation, } \\
\text { post-operative morbidity, survival } \\
\text { and recurrence rates are similar } \\
\text { (see table } 3 \text { ). }\end{array}$ \\
\hline $\begin{array}{l}\text { Dutch TME } \\
\text { Trial }[16,38]\end{array}$ & $\begin{array}{l}937 \text { TME only } \\
924 \text { pre-operative } \\
\text { RT + TME within } \\
1 \text { week }\end{array}$ & $\begin{array}{l}\text { median } 24.9 \\
\text { months } \\
(1.1-56)[16]\end{array}$ & $\begin{array}{l}\text { overall survival: } \\
2 \text { years: } 82 \text { vs. } 81.8 \%(\mathrm{p}=0.84) \\
5 \text { years: } 63.5 \text { vs. } 64.3 \%(\mathrm{NS}) \\
\text { local recurrence: overall } 5.3 \% \\
2 \text { years: } 2.4 \text { vs. } 8.2 \%(\mathrm{p}<0.001) \\
\text { stage I: } 0.5 \text { vs. } 0.7 \%(\mathrm{p}=0.15) \\
\text { stage II: } 1.0 \text { vs. } 5.7 \%(\mathrm{p}=0.01) \\
\text { stage III: } 4.3 \text { vs. } 15 \%(\mathrm{p}<0.001) \\
5 \text { years: } 5.8 \text { vs. } 11.4 \%(\mathrm{p}<0.001)\end{array}$ & $\begin{array}{l}\text { Pre-operative SCRT reduces local } \\
\text { recurrence but does not affect } \\
\text { overall survival. This benefit is } \\
\text { above that obtained with TME. } \\
\text { Overall recurrence of } 5.3 \% \text { is } \\
\text { consistent with TME surgery. } \\
\text { The SCRT benefit is not observed } \\
\text { in stage I cancer when TME is } \\
\text { employed. }\end{array}$ \\
\hline \multirow[t]{3}{*}{$\begin{array}{l}\text { Swedish } \\
\text { Rectal Cancer } \\
\text { Trial [13] }\end{array}$} & $\begin{array}{l}454 \text { surgery only } \\
454 \text { pre-operative } \\
\text { RT + surgery } \\
\text { within } 1 \text { week }\end{array}$ & $\begin{array}{l}\text { median } \\
13 \text { years } \\
(11.5-15)\end{array}$ & $\begin{array}{l}\text { overall survival: } \\
\text { stage I: } 54 \text { vs. } 45 \%(p=0.31) \\
\text { stage II: } 38 \text { vs. } 30 \%(p=0.27) \\
\text { stage III: } 18 \text { vs. } 16 \%(p=0.18) \\
\text { overall: } 38 \text { vs. } 30 \%(p=0.008)\end{array}$ & $\begin{array}{l}\text { Pre-operative SCRT improves } \\
\text { overall and disease-specific survival } \\
\text { and local recurrence at long-term } \\
\text { follow-up. }\end{array}$ \\
\hline & & & $\begin{array}{l}\text { cancer-specific survival: } \\
\text { stage I: } 4.5 \text { vs. } 14 \%(\mathrm{p}=0.009) \\
\text { stage II: } 6 \text { vs. } 22 \%(\mathrm{p}<0.001) \\
\text { stage III: } 23 \text { vs. } 46 \%(\mathrm{p}<0.001) \\
\text { overall: } 72 \text { vs. } 62 \%(\mathrm{p}=0.03)\end{array}$ & $\begin{array}{l}\text { SCRT leads to increased cancer- } \\
\text { specific survival in all stages. }\end{array}$ \\
\hline & & & $\begin{array}{l}\text { local recurrence: } \\
\text { stage I: } 4.5 \text { vs. } 14 \%(\mathrm{p}=0.009) \\
\text { stage II: } 6 \text { vs. } 22 \%(\mathrm{p}<0.001) \\
\text { stage III: } 23 \text { vs. } 46 \%(\mathrm{p}<0.001) \\
\text { overall: } 9 \text { vs. } 26 \%(\mathrm{p}<0.001)\end{array}$ & $\begin{array}{l}\text { Decrease in local recurrence in } \\
\text { all stages. However, this was prior } \\
\text { to TME. Results biased by 'poor } \\
\text { surgery' (e.g. overall recurrence } \\
26 \%, 14 \% \text { in stage I). }\end{array}$ \\
\hline
\end{tabular}


Table 4 (continued)

\begin{tabular}{|c|c|c|c|c|}
\hline Study & Design & Follow-up & Results & Conclusion/remarks \\
\hline $\begin{array}{l}\text { Stockholm II } \\
\text { [39] }\end{array}$ & $\begin{array}{l}557 \text { patients } \\
272 \text { SCRT } \\
(5 \times 5 \text { Gy })+ \\
\text { immediate surgery } \\
285 \text { surgery only }\end{array}$ & $\begin{array}{l}\text { median } \\
8.8 \text { years }\end{array}$ & $\begin{array}{l}\text { local recurrence } \\
\text { SCRT: } 12 \text { vs. } 25 \%(\mathrm{p}<0.001) \\
\text { overall survival } \\
\text { SCRT: } 46 \text { vs. } 39 \%(\mathrm{p}<0.03) \\
\text { post-operative mortality } \\
\text { SCRT: } 5 \text { vs. } 1 \%(\mathrm{p}=0.02)\end{array}$ & $\begin{array}{l}\text { SCRT reduces local recurrence and } \\
\text { increases overall survival. Patients } \\
\text { were restricted to }<80 \text { years in this } \\
\text { trial. Higher mortality risk with } \\
\text { SCRT reduces benefit in elderly } \\
\text { patients. }\end{array}$ \\
\hline $\begin{array}{l}\text { Stockholm I } \\
\text { [29] }\end{array}$ & $\begin{array}{l}849 \text { patients } \\
424 \text { SCRT } \\
(5 \times 5 \text { Gy })+ \\
\text { immediate surgery } \\
425 \text { surgery only }\end{array}$ & $\begin{array}{l}\text { median } \\
107 \text { months } \\
(62-144)\end{array}$ & $\begin{array}{l}684 \text { curative } \\
\text { local recurrence: total } 24.7 \%(160 / 684) \\
\text { all stages: } 16 \text { vs. } 30 \%(\mathrm{p}<0.01) \\
\text { Duke's A: } 6.1 \text { vs. } 9.9 \%(\mathrm{p}=\mathrm{NS}) \\
\text { Duke's B: } 15.6 \text { vs. } 43.3 \%(\mathrm{p}<0.001) \\
\text { Duke's C: } 29.0 \text { vs. } 43.3 \%(\mathrm{p}=0.068) \\
\text { post-operative mortality } \\
\text { SCRT: } 8 \text { vs. } 2 \%(\mathrm{p}<0.01)\end{array}$ & $\begin{array}{l}\text { Pre-operative SCRT decreases local } \\
\text { recurrence in all tumour stages. } \\
\text { No difference in overall survival } \\
\text { but SCRT leads to higher early } \\
\text { post-operative mortality } \\
\text { (see section on morbidity and } \\
\text { mortality). }\end{array}$ \\
\hline
\end{tabular}

patients in this group would receive post-operative CT, which would influence survival data. A similar trial (TROG 44) is underway comparing SCRT with LCCRT [2]. Further trials will be required to establish whether the differences between the two treatment arms in the Polish trial and TROG 44 are due to the RT dose regime (short high-dose fractions or extended low-dose fractions), concurrent CT or the different time interval to surgery. Stockholm III should answer some of these questions.

\section{Interval to Surgery - Immediate or Delayed (Lyon 90-01)}

The optimal time interval between RT and surgery is unknown. There is a trend towards greater downstaging and complete response with increasing interval between LCCRT and surgery [24]. There is almost no trial evidence of SCRT and delayed surgery as SCRT was designed to minimise delay to surgery. The Lyon 90-01 trial randomised $201 \mathrm{~T} 2 / 3$ mid- and low-rectal cancer patients to pre-operative $13 \times 3$ Gy RT (not SCRT) followed by a short interval (SI, within 2 weeks) or long interval (LI, 6-8 weeks) to surgery. The trial was powered on the basis that sphincter-preserving surgery would be possible in $70 \%$ of patients in the LI group compared to $50 \%$ of patients in the SI group, i.e. $20 \%$ difference in sphincter preservation. The limitations of using sphincter preser- vation as an end point have already been discussed in the Polish trial [21].

LI demonstrated better tumour response (72 vs. 53\%) and pathological downstaging (26 vs. $10 \%$ ), confirmed by more frequent pathological T0/1 tumours in the LI group (28.7 vs. $15.2 \%)$ and more frequent nodal involvement in the SI group (16.3 vs. 5\%). There was a trend towards increased sphincter preservation in the LI group (76 vs. $68 \%$ ) which was not statistically significant, possibly because the study was powered to detect a substantial $20 \%$ difference, or surgeon reluctance as discussed earlier. There was no significant difference in 3-year overall survival ( 81 vs. $73 \%$ ), local recurrence ( 10.3 vs. $9.9 \%$ ), early post-operative mortality ( 3 vs. $4 \%$ ) or morbidity (18 vs. $17 \%)$ even though the LI group had greater downstaging which impacts on important prognostic factors such as the ability to obtain clear resection margins $[21,25]$. Recurrence rate in patients with $<15 \mathrm{~mm}$ distal resection margins was $16.3 \%$ (7/43), again proving that neither RT schedule compensates for margin involvement as reported in the Dutch and other trials $[18,19]$.

The $13 \times 3$ Gy in this trial treatment differs from $5 \times$ 5 Gy SCRT [2]. There is no evidence of $5 \times 5$ Gy SCRT with delayed surgery. The Stockholm III trial compares $5 \times 5 \mathrm{~Gy}+$ immediate surgery versus $5 \times 5 \mathrm{~Gy}+$ delayed surgery versus $25 \times 2 \mathrm{~Gy}+$ delayed surgery. The results will provide eagerly anticipated information on the effects of the interval between pre-operative irradiation and surgery on tumour downstaging, CRM involvement 
and recurrence rates. A more ambitious trial investigating not only the effect of a delayed surgery following SCRT, but also the use of local excision with transanal endoscopic microsurgery (TEM) in ERUS-/MRI-staged T1/2 rectal cancer is being developed in the UK [pers. commun.]. TREC (TRansanal Endoscopic microsurgery in early rectal Cancer) is a randomised phase 2 trial comparing SCRT + TEM in 5 days versus SCRT + TEM after 6 weeks. This trial will hopefully provide information not only on tumour downstaging 6 weeks after SCRT, but also on feasibility of TEM (as opposed to TME) in early cancer.

\section{Local Failure and Targeted RT}

Pre-operative SCRT leads to lower local recurrence but at the expense of increased morbidity, which is fieldand dose-dependant. Hence, targeted RT with reduced irradiation volume should lead to decreased morbidity whilst hopefully maintaining local control. Syk et al. [26] analysed the location and radiological appearances of 33 local recurrences following TME. The majority of recurrences (29/33) occurred in lower $2 / 3$ of the pelvis. Fourteen occurred in the upper rectum, 9 of which did not receive RT post-operatively. Furthermore, 12 of the 14 had radiological signs of residual mesorectal fat, which suggests that residual mesorectal fat coupled with nonradiation leads to recurrence. Only $2 / 33$ recurrences originated from the lateral pelvic lymph nodes, neither of which had received pre-operative RT. This figure was extrapolated to suggest that lateral node involvement was responsible for only $0.2 \%$ of all local recurrences. Hence, reducing the upper and lateral borders may provide similar local control but with less morbidity.

The TREC trial uses a reduced-field SCRT around the mesorectum to minimise long-term SCRT-induced morbidity as routine irradiation of lateral field is excessive in such early cancers. Although reduction of field volume is known to decrease the morbidity of SCRT (as elegantly chronicled in Stockholm I, II and the Swedish Rectal Cancer Trial), it is not clear whether further reduction of field would maintain similar local control [11]. An alternative strategy would be to reduce the delivered dose. This alternative was explored by Saunders et al. [27] who described their experiences of $20 \mathrm{~Gy}(4 \times 5$ Gy fractions). This retrospective audit demonstrated similar 5-year local recurrence when compared with the Dutch trial, suggesting that a lower total dose may be considered in future trials. The Lyon 90-01 trial used a modified $13 \times 3$
Gy with acceptable survival and morbidity [22]. Unfortunately, the Saunders et al. [27] study retrospective audit design precluded any reliable morbidity data. Even if morbidity is decreased, it cannot be assumed that this is purely due to reduced RT. The radiobiological effects of SCRT are unknown and implications of reduced dose on local control are unclear. The meta-analysis by Gray et al. [3] showed decreased local control with $<30$ Gy. Similarly, the German Rectal Cancer Trial highlighted loss of local control when patients received sub-optimal dose $(<43 \mathrm{~Gy})$, with local recurrence increasing from 6 to $21 \%$ and resulting reduction in disease-free survival from 69 to $57 \%$ [12]. Further studies of modified RT technique will have implications on reducing morbidity without loss of disease control, and tailoring individual 'patientspecific' RT.

\section{Morbidity and Toxicity of SCRT and LCCRT}

A recent Cochrane Database Review compared preoperative RT with pre-operative LCCRT and concluded that pre-operative LCCRT achieved superior local control, which again did not translate to disease-free or overall survival benefit (table 3 ) $[6,8,21,28]$. The importance of this is that whilst addition of CT reduces local recurrence, increases downstaging and perhaps $\mathrm{R} 0$ rates, it does not affect sphincter preservation or the long-term probability of metastatic disease. Future trials need to address eradication of metastatic disease. Also, pre-operative CRT has higher toxicity and more arduous regime which may not be acceptable by frail patients. Such patients may benefit from SCRT. Although the cancer outcomes of SCRT have been extensively published, emerging evidence of SCRT-induced long-term dysfunction needs to be considered and is summarized (table 5).

The adverse effects of SCRT are related to dose, volume, beam technique and shielding. The Stockholm I trial reported increased early mortality with SCRT (8 vs. $2 \%)[29,30]$. SCRT was also associated with increased thromboembolism, femoral neck and pelvic fractures, post-operative fistulation but not arterial or genitourinary tract diseases. This was largely due to the two-beam technique and wide $\left(\mathrm{L}_{2}\right)$ target field [30]. The technique was modified to a 3/4 beam technique in the Stockholm II trial, which reported a non-significant trend toward increased post-operative mortality with SCRT. This was attributed to lack of shielding. The Swedish Rectal Cancer Trial demonstrated identical mortality rates between SCRT and non-radiated patients (2.6\%) when the $3 / 4$ 
Table 5. Morbidity and mortality following SCRT $(5 \times 5$ Gy)

\begin{tabular}{|c|c|c|c|}
\hline Study & RT & Follow-up & Results \\
\hline MRC-CR07 & $\begin{array}{l}5 \times 5 \mathrm{~Gy} \\
25 \times 2 \mathrm{~Gy}\end{array}$ & 3 years & $\begin{array}{l}\text { SCRT increases incontinence but does no affect overall function. } \\
\text { SCRT affects sexual function borderline significance }(\mathrm{p}=0.051) \text {. } \\
\text { Most significant sexual deterioration attributable to TME surgery, } \\
\text { with SCRT compounding damage. }\end{array}$ \\
\hline Dutch TME Trial [32] & $\begin{array}{l}5 \times 5 \mathrm{~Gy} \\
3 / 4 \text { beam } \\
\text { mid- } \mathrm{L}_{5}\end{array}$ & 5.1 years & $\begin{array}{l}\text { RT associated with increased faecal incontinence ( } 62 \text { vs. } 38 \% ; \\
p<0.001) \text {, blood loss }(11 \text { vs. } 3 \% ; p=0.004) \text {, mucus loss }(27 \text { vs. } 15 \% ; \\
\text { p }=0.005) \text {. Irradiated patients report lower satisfaction with bowel } \\
\text { function, greater impact on daily activities but no difference in overall } \\
\text { perception of health. }\end{array}$ \\
\hline $\begin{array}{l}\text { Swedish Rectal Cancer } \\
\text { Trial }[31,40]\end{array}$ & $\begin{array}{l}5 \times 5 \text { Gy } \\
3 / 4 \text { beam } \\
\text { mid- } \mathrm{L}_{4}\end{array}$ & & $\begin{array}{l}\text { Increased risk of early re-admission due to gastrointestinal causes. } \\
\text { No increase in late readmissions. Increased relative risk for admission } \\
\text { due to unspecified infections, bowel obstruction, abdominal pain. }\end{array}$ \\
\hline \multirow[t]{2}{*}{ Stockholm I and II [30] } & $\begin{array}{l}\text { Stockholm I } \\
5 \times 5 \text { Gy } \\
2 \text { beam } \\
\text { mid- } \mathrm{L}_{2}\end{array}$ & $\begin{array}{l}\text { Stockholm I } \\
140 \text { months } \\
(95-178)\end{array}$ & $\begin{array}{l}\text { Increased risk of venous thromboembolism ( } 7.5 \text { vs. } 3.6 \%) \text {, } \\
\text { femoral neck/pelvic fractures ( } 5.3 \text { vs. } 2.4 \%) \text {, intestinal obstruction } \\
(13.3 \text { vs. } 8.5 \%) \text { and fistula ( } 4.8 \text { vs. } 2.3 \%) \text {. }\end{array}$ \\
\hline & $\begin{array}{l}\text { Stockholm II } \\
5 \times 5 \text { Gy } \\
3 / 4 \text { beam } \\
\text { mid- } \mathrm{L}_{4} \\
\text { ?shielding }\end{array}$ & $\begin{array}{l}\text { Stockholm II } \\
62 \text { months } \\
(19-95)\end{array}$ & $\begin{array}{l}\text { Increased risk of cardiovascular death in year } 1 \text { (Stockholm I and II). } \\
\text { Increased risk of death in subsequent years, any cause } \\
\text { (Stockholm I only, not Stockholm II). }\end{array}$ \\
\hline
\end{tabular}

beam technique was combined with adequate shielding $[11,31]$. This was also confirmed in the Dutch TME Trial [32]. Another source of morbidity is perineal wound complications which increase following RT. SCRT was associated with $26 \%$ perineal complications as opposed to $18 \%$ in the non-irradiated group [16]. The Dutch TME Trial reported higher complications in the irradiated group (31 vs. $18.5 \%)$ and this is confirmed in the Swedish trials [31, 32].

\section{Functional Morbidity}

TME achieves lowest local recurrence rates but is associated with significant morbidity. This morbidity extends from the immediate post-operative period (e.g. dehiscence) to long-term gastrointestinal and genitourinary dysfunction. RT compounds the severity of dysfunction. This must be taken into account when deciding if RT should be offered for patients with already low recurrence rates with 'good' TME surgery. EORTC 22921 and Dutch TME Trial reported increased faecal inconti- nence following SCRT $[8,30,32]$ (table 5). However, there were different definitions of 'continence' and methods of assessment. MRC-CR07 used EORTC QLQ-CR38 to assess gastrointestinal and sexual function (table 5). There was no difference in overall function but patients receiving SCRT had higher incontinence. The striking results were that the most dramatic decrease in sexual function occurred equally in both groups, and in the first 6 months following surgery. This dysfunction then plateaus with a minimal difference between both groups at longer follow-up. This suggests that TME, not SCRT, is the primary cause for the immediate and the persisting long-term dysfunction. SCRT merely compounds the damage caused by surgery as can be seen by significant differences in sexual function in the longer-term (neither of which return to baseline pre-operative levels). However, these differences are small compared with the initial decrease following surgery. These results suggest that TME and SCRT combination is excessive in early cancers where SCRT does not sufficiently improve outcomes (CR-07 shows no local recurrence benefit in stage I cancer) to justify routine radiation and related morbidity. It is also 
becoming increasingly apparent that local recurrence should not be the only measure of treatment success as function and quality of life are also significantly altered. As such, future treatment for these (stage I) tumours may involve TME only or SCRT and local excision or other less invasive surgical methods in conjunction with radiation +/- CT.

\section{Summary and Direction for Future Trials}

Each patient requires an individually tailored RT regime and salient points below will help with future decision-making.

- SCRT does not significantly alter recurrence/survival beyond what is achievable by 'good' TME surgery in stage I cancer. SCRT should not be used routinely in T1 rectal cancer and only selectively in T2 cancer, especially when TME is performed, due to minimal survival benefit and the combined morbidity of both surgery and RT. The individual patient needs, co-morbidity and expected survival should be included in this decision.

- SCRT may have an important role in the development of alternative surgical therapies for T1/2 cancer. A trial of SCRT and local excision by TEM is being developed in the UK (TREC). Another phase 2 trial of local excision (non-TEM) and LCCRT is ongoing in the USA (Z6041) [33]. Neo-adjuvant therapy followed by local excision may be an acceptable trade-off to TME. These less invasive approaches may have comparable (or slightly higher) recurrence but in exchange for avoidance of surgical mortality, morbidity, stoma and gastrointestinal/ genitourinary dysfunction.

- The experience of Papillon style contact RT on selected early cancer is published [34]. The International Contact Radiotherapy Evaluation (ICONE) group has launched the CONTEM trial (Observational Study on Contact X-Ray and Transanal Endoscopic Microsurgery) for selected T1-3 tumours using combinations of transanal excision, contact RT and concomitant CT [35]. The current limitations are availability of specialised RT equipment and highly selective patient population.

- LCCRT is the standard of care for T3/4 cancer. SCRT and delayed surgery may prove a valuable alternative to LCCRT where cost, logistics of daily hospital visits and toxicity of concomitant CT are not acceptable to some patients. This would represent an interesting expansion and significant shift from the original role of SCRT.

- Combination therapy with new agents such as epidermal growth factor receptors and vascular endothelial growth factors may increase downstaging and reduce metastases in combination with LCCRT but is not possible with SCRT $[36,37]$.

- Improvements in radiological staging are required if any of the above pathways are to be followed. At present, if staging cannot be accurately predicted, the surgical/oncological decision should be based on the number of patients harmed by unnecessary toxic treatment to modify one recurrence.

Future improvements in early rectal cancer lie in minimising surgical trauma (e.g., combination irradiation and local excision), radiological assessment, identifying poor prognostic factors and developing new treatments which target the small proportion of patients who develop systemic metastases, but also account for most of the disease-related death in this group.

\section{Conclusion}

The optimal regime remains unclear, and eagerly awaited results of trials are unlikely to formulate a blanket treatment policy for individual stage cancers. The role of SCRT may be evolving, especially in conjunction with delayed interval to surgery, local excision, and possibly in T3 cancers. Other prognostic indicators/selection criteria need to be identified. The cornerstone for neo-adjuvant treatment in the foreseeable future remains individual patient assessment. Local recurrence rates do not reflect survival or function. Trials require alternative end points which address other issues such as metastases and quality of life rather than local recurrence alone.

\section{Addendum}

Between time of acceptance and publication, the full results of the MRC-CR07 have been published in the Lancet. Sebag-Montefiore D, Stephens RJ, Steele R, Monson J, Grieve R, Khanna S, Quirke P, Couture J, de Metz C, Myint AS, Bessell E, Griffiths G, Thompson LC, Parmar M: Preoperative radiotherapy versus selective postoperative chemoradiotherapy in patients with rectal cancer (MRC CR07 and NCIC-CTG C016): a multicentre, randomised trial. Lancet 2009;373:811-820. 


\section{References}

1 Heald RJ, Ryall RD: Recurrence and survival after total mesorectal excision for rectal cancer. Lancet 1986;1:1479-1482.

$\checkmark 2$ Ortholan C, Francois E, Thomas O, Benchimol D, Baulieux J, Bosset JF, Gerard JP: Role of radiotherapy with surgery for $\mathrm{T} 3$ and resectable T4 rectal cancer: evidence from randomized trials. Dis Colon Rectum 2006;49: 302-310.

-3 Colorectal Cancer Collaborative Group: Adjuvant radiotherapy for rectal cancer: a systematic overview of 8,507 patients from 22 randomised trials. Lancet 2001;358:12911304.

4 Mohiuddin M, Marks J, Marks G: Management of rectal cancer: short- vs. long-course preoperative radiation. Int J Radiat Oncol Biol Phys 2008;72:636-643.

5 Glimelius B: Radiotherapy in rectal cancer. Br Med Bull 2002;64:141-157.

6 Ceelen WP, Van Nieuwenhove Y, Fierens K: Preoperative chemoradiation versus radiation alone for stage II and III resectable rectal cancer. Cochrane Database Syst Rev 2009: CD006041.

-7 Sauer R, Becker H, Hohenberger W, Rodel C, Wittekind C, Fietkau R, Martus P, Tschmelitsch J, Hager E, Hess CF, Karstens JH, Liersch T, Schmidberger H, Raab R: Preoperative versus postoperative chemoradiotherapy for rectal cancer. N Engl J Med 2004; 351:1731-1740.

-8 Bosset JF, Calais G, Daban A, Berger C, Radosevic-Jelic L, Maingon P, Bardet E, Pierart M, Briffaux A: Preoperative chemoradiotherapy versus preoperative radiotherapy in rectal cancer patients: assessment of acute toxicity and treatment compliance. Report of the 22921 randomised trial conducted by the EORTC Radiotherapy Group. Eur J Cancer 2004;40:219-224.

-9 Collette L, Bosset JF, den Dulk M, Nguyen F, Mineur L, Maingon P, Radosevic-Jelic L, Pierart M, Calais G: Patients with curative resection of cT3-4 rectal cancer after preoperative radiotherapy or radiochemotherapy: does anybody benefit from adjuvant fluorouracil-based chemotherapy? A trial of the European Organisation for Research and Treatment of Cancer Radiation Oncology Group. J Clin Oncol 2007;25:4379-4386.

$\checkmark 10$ Gerard JP, Conroy T, Bonnetain F, Bouche O, Chapet O, Closon-Dejardin MT, Untereiner M, Leduc B, Francois E, Maurel J, Seitz JF, Buecher B, Mackiewicz R, Ducreux M, Bedenne L: Preoperative radiotherapy with or without concurrent fluorouracil and leucovorin in T3-4 rectal cancers: results of FFCD 9203. J Clin Oncol 2006;24:4620-4625.

-11 Glimelius B, Isacsson U: Preoperative radiotherapy for rectal cancer - is $5 \times 5$ Gy a good or a bad schedule? Acta Oncol 2001;40:958967.

12 Fietkau R, Rodel C, Hohenberger W, Raab R, Hess C, Liersch T, Becker H, Wittekind C,
Hutter M, Hager E, Karstens J, Ewald H, Christen N, Jagoditsch M, Martus P, Sauer R: Rectal cancer delivery of radiotherapy in adequate time and with adequate dose is influenced by treatment center, treatment schedule, and gender and is prognostic parameter for local control: results of study CAO/ARO/ AIO-94. Int J Radiat Oncol Biol Phys 2007; 67:1008-1019.

13 Folkesson J, Birgisson H, Pahlman L, Cedermark B, Glimelius B, Gunnarsson U: Swedish Rectal Cancer Trial: long lasting benefits from radiotherapy on survival and local recurrence rate. J Clin Oncol 2005;23:56445650.

14 Nagtegaal ID, Marijnen CA, Kranenbarg EK, van de Velde CJ, van Krieken JH: Circumferential margin involvement is still an important predictor of local recurrence in rectal carcinoma: not one millimeter but two millimeters is the limit. Am J Surg Pathol 2002;26:350-357.

15 Quirke P, Sebag-Montefiore D, Steele R, et al: Local recurrence after rectal cancer resection is strongly related to the plane of surgical dissection and is further reduced by preoperative short course radiotherapy (abstract). J Clin Oncol 2006;24:A3512.

16 Kapiteijn E, Marijnen CA, Nagtegaal ID, Putter H, Steup WH, Wiggers T, Rutten HJ, Pahlman L, Glimelius B, van Krieken JH, Leer JW, van de Velde CJ: Preoperative radiotherapy combined with total mesorectal excision for resectable rectal cancer. N Engl J Med 2001;345:638-646.

17 Marijnen CA, Nagtegaal ID, Kapiteijn E, Kranenbarg EK, Noordijk EM, van Krieken JH, van de Velde CJ, Leer JW: Radiotherapy does not compensate for positive resection margins in rectal cancer patients: report of a multicenter randomized trial. Int J Radiat Oncol Biol Phys 2003;55:1311-1320.

$\checkmark 18$ Peeters KC, Marijnen CA, Nagtegaal ID, Kranenbarg EK, Putter H, Wiggers T, Rutten H, Pahlman L, Glimelius B, Leer JW, van de Velde CJ: The TME trial after a median follow-up of 6 years: increased local control but no survival benefit in irradiated patients with resectable rectal carcinoma. Ann Surg 2007;246:693-701.

19 Baik SH, Kim NK, Lee YC, Kim H, Lee KY, Sohn SK, Cho CH: Prognostic significance of circumferential resection margin following total mesorectal excision and adjuvant chemoradiotherapy in patients with rectal cancer. Ann Surg Oncol 2007;14:462-469.

20 Sebag-Montefiore D, Steele R, Quirke P, Grieve RJ, Khanna S, Monson J, Holliday A, Thompson L, Griffiths G, Stephens R, NCCSGaC participants: Routine short course pre-op radiotherapy or selective postop chemoradiotherapy for resectable rectal cancer? Preliminary results of the MRC CR07 randomised trial; in 2006 ASCO Annu Meet. J Clin Oncol 2006:A3511.
21 Bujko K, Nowacki MP, Nasierowska-Guttmejer A, Michalski W, Bebenek M, Kryj M: Long-term results of a randomized trial comparing preoperative short-course radiotherapy with preoperative conventionally fractionated chemoradiation for rectal cancer. Br J Surg 2006;93:1215-1223.

22 Francois Y, Nemoz CJ, Baulieux J, Vignal J, Grandjean JP, Partensky C, Souquet JC, Adeleine P, Gerard JP: Influence of the interval between preoperative radiation therapy and surgery on downstaging and on the rate of sphincter-sparing surgery for rectal cancer: the Lyon R90-01 randomized trial. J Clin Oncol 1999;17:2396.

23 Habr-Gama A: Assessment and management of the complete clinical response of rectal cancer to chemoradiotherapy. Colorectal Dis 2006;8(suppl 3):21-24.

24 Moore HG, Gittleman AE, Minsky BD, Wong D, Paty PB, Weiser M, Temple L, Saltz L, Shia J, Guillem JG: Rate of pathologic complete response with increased interval between preoperative combined modality therapy and rectal cancer resection. Dis Colon Rectum 2004;47:279-286.

25 Bujko K, Michalski W, Kepka L, Nowacki MP, Nasierowska-Guttmejer A, Tokar P, Dymecki D, Pawlak M, Lesniak T, Richter P, Wojnar A, Chmielik E: Association between pathologic response in metastatic lymph nodes after preoperative chemoradiotherapy and risk of distant metastases in rectal cancer: an analysis of outcomes in a randomized trial. Int J Radiat Oncol Biol Phys 2007;67: 369-377.

26 Syk E, Torkzad MR, Blomqvist L, Ljungqvist O, Glimelius B: Radiological findings do not support lateral residual tumour as a major cause of local recurrence of rectal cancer. $\mathrm{Br}$ J Surg 2006;93:113-119.

-27 Saunders MP, Alderson H, Chittalia A, Hughes S, James RD, Armstrong G, Swindell $\mathrm{R}$, Scott NA: Preoperative radiotherapy for operable rectal cancer - is a lower dose to a reduced volume acceptable? Clin Oncol (R Coll Radiol) 2006;18:594-599.

28 Boulis-Wassif S, Gerard A, Loygue J, Camelot D, Buyse M, Duez N: Final results of a randomized trial on the treatment of rectal cancer with preoperative radiotherapy alone or in combination with 5-fluorouracil, followed by radical surgery. Trial of the European Organization on Research and Treatment of Cancer Gastrointestinal Tract Cancer Cooperative Group. Cancer 1984;53: 1811-1818.

29 Cedermark B, Johansson H, Rutqvist LE, Wilking N: The Stockholm I trial of preoperative short term radiotherapy in operable rectal carcinoma. A prospective randomized trial. Stockholm Colorectal Cancer Study Group. Cancer 1995;75:2269-2275.

- 30 Holm T, Singnomklao T, Rutqvist LE, Cedermark B: Adjuvant preoperative radio- 
therapy in patients with rectal carcinoma. Adverse effects during long term follow-up of two randomized trials. Cancer 1996;78: 968-976.

- 31 Birgisson H, Pahlman L, Gunnarsson U, Glimelius B: Adverse effects of preoperative radiation therapy for rectal cancer: longterm follow-up of the Swedish Rectal Cancer Trial. J Clin Oncol 2005;23:8697-8705.

- 32 Peeters KC, van de Velde CJ, Leer JW, Martijn H, Junggeburt JM, Kranenbarg EK, Steup WH, Wiggers T, Rutten HJ, Marijnen CA: Late side effects of short-course preoperative radiotherapy combined with total mesorectal excision for rectal cancer: increased bowel dysfunction in irradiated patients - a Dutch colorectal cancer group study. J Clin Oncol 2005;23:6199-6206.
33 Ota DM, Nelson H: Local excision of rectal cancer revisited: ACOSOG protocol Z6041. Ann Surg Oncol 2007;14:271.

34 Sun Myint A, Grieve RJ, McDonald AC, Levine EL, Ramani S, Perkins K, Wong H, Makin CA, Hershman MJ: Combined modality treatment of early rectal cancer: the UK experience. Clin Oncol (R Coll Radiol) 2007;19:674-681.

35 Lindegaard J, Gerard JP, Sun Myint A, Myerson R, Thomsen H, Laurberg S: Whither papillon? Future directions for contact radiotherapy in rectal cancer. Clin Oncol (R Coll Radiol) 2007;19:738-741.

36 Horisberger K, Treschl A, Mai S, BarretoMiranda M, Kienle P, Strobel P, Erben P, Woernle C, Dinter D, Kahler G, Hochhaus A, Post S, Willeke F, Wenz F, Hofheinz RD: Cetuximab in combination with capecitabine, irinotecan, and radiotherapy for patients with locally advanced rectal cancer: results of a phase II MARGIT trial. Int J Radiat Oncol Biol Phys 2009; Epub ahead of print.
37 Watanabe T: Chemoradiotherapy and adjuvant chemotherapy for rectal cancer. Int J Clin Oncol 2008;13:488-497.

38 Marijnen C, Peeters K, Putter H: Long term results, toxicity and quality of life in the TME trial; in ESTRO Meet, Amsterdam, 2004.

39 Martling A, Holm T, Johansson H, Rutqvist LE, Cedermark B: The Stockholm II trial on preoperative radiotherapy in rectal carcinoma: long-term follow-up of a populationbased study. Cancer 2001;92:896-902.

40 Improved survival with preoperative radiotherapy in resectable rectal cancer. Swedish Rectal Cancer Trial. N Engl J Med 1997;336: 980-987. 